\title{
PRODUTIVIDADE E QUALIDADE DE FRUTOS DO MARACUJAZEIRO-AMARELO SUBMETIDO À PODA DE RAMOS PRODUTIVOS ${ }^{1}$
}

\author{
OSCAR MARIANO HAFLE ${ }^{2}$, JOSÉ DARLAN RAMOS ${ }^{3}$, LUIZ CARLOS DE OLIVEIRA LIMA ${ }^{4}$, \\ ESTER ALICE FERREIRA ${ }^{5}$, PAULO CÉSAR DE MELO ${ }^{6}$
}

RESUMO - A determinação da forma inicial a ser dada a uma planta é decisiva para o manejo cultural e fitosanitário, assim como apresenta efeitos na produtividade e qualidade dos frutos colhidos. O presente trabalho teve como objetivo estabelecer o número adequado de ramos produtivos (terciários) e conhecer o seu efeito na produção, produtividade e qualidade dos frutos de maracujazeiro-amarelo (Passiflora edulis Sims $f$. flavicarpa Deg.). O experimento foi instalado e conduzido em pomar comercial no município de Lavras-MG (21 ${ }^{\circ} 14^{\prime} \mathrm{S} ; 45^{\circ} 58^{\prime} \mathrm{W}$; $910 \mathrm{~m}$ de altitude), entre os meses de setembro de 2005 a julho de 2006 , utilizando plantas oriundas de sementes, plantadas no espaçamento de $4 \mathrm{~m}$ entre plantas e $3 \mathrm{~m}$ entre as linhas, conduzidas em espaldeira vertical com um fio de arame na altura de $180 \mathrm{~cm}$. Os tratamentos constaram de diferentes números de ramos produtivos, sendo eles: 40; 30;24; 20 e 14 ramos por planta. O delineamento utilizado foi em blocos casualizados, com quatro repetições, sendo a parcela composta por três plantas. Avaliaram-se a produtividade e o rendimento de suco ( $\mathrm{t} / \mathrm{ha})$, número de frutos por planta, peso médio dos frutos, diâmetro longitudinal e transversal do fruto $(\mathrm{mm})$, espessura da casca $(\mathrm{mm})$, porcentagem de casca, semente e suco, sólidos solúveis totais e acidez total titulável. Houve diferença estatística significativa para as variáveis: número de frutos por planta, produtividade, rendimento de suco e peso médio dos frutos. As plantas com menor número de ramos produtivos tiveram a produtividade e o número de frutos reduzidos, com o peso médio do fruto aumentado sem, no entanto, modificar as suas características internas.

Termos para indexação: Passiflora edulis Sims $f$. flavicarpa Deg., espaldeira, poda, rendimento, qualidade.

\section{PRODUCTIVITY AND QUALITY OF FRUIT IN YELLOW PASSION FRUIT TREE SUBMITTED TO PRUNING OF PRODUCTIVE BRANCHES}

\begin{abstract}
The determination of the initial structure to be given to the plant is decisive for cultural and fitosanitary management, presenting also effects on productivity and quality of harvested fruits. The present work aimed to establish the appropriate number of productive branches (tertiary) and to know this effect on production, productivity and quality of the yellow passion fruit (Passiflora edulis Sims f. Alavicarpa Deg.). The experiment was carried out in a commercial orchard located in Lavras county, Minas Gerais, Brazil ( $21^{\circ}$ 14 ' S.; $45^{\circ} 58$ ' WGr.; 916 m of altitude), from September of 2005 to July of 2006, using seedlings which were planted in 4 × 3m spacing, plants and lines respectively, led in vertical cordon with a wire thread at 180 $\mathrm{cm}$ high. The treatments consisted of number of productive branches, being 40, 30, 24, 20 and 14 branches per plant. The experimental design used was randomized blocks, with four repetitions, with three plants for split. It was evaluated the productivity and juice yield ( $\mathrm{t} / \mathrm{ha}$ ), number of fruits/plant, medium weight of the fruits, longitudinal and traversal diameter of the fruits $(\mathrm{mm})$, thickness of the peel $(\mathrm{mm})$. There was significant statistics difference for number of fruits/plant, productivity, juice yield and medium weight of the fruits. The plants within smaller number of tertiary branches presented reduced productivity and number of fruits/plant and also increasing of medium weight of fruits, without however, modify the fruit internal characteristics. Index terms: Passiflora edulis Sims f. flavicarpa Deg., vertical cordon, prunning, yield quality.
\end{abstract}

\footnotetext{
${ }^{1}$ (Trabalho 180-08). Recebido em: 11-07-2008. Aceito para publicação em: 04-05-2009.

${ }^{2}$ Dr. em Agronomia/Fitotecnia, Universidade Federal de Lavras (UFLA), Cx. Postal 3037, Lavras-MG, CEP 37200-000. Prof. do Inst. Fed. de Educação, Ciência e Tecnologia da Paraíba, Campus de Sousa-PB, email: omhafle@yahoo.com.br, Autor correspondente

${ }^{3}$ Dr. Prof. Dep. de Agricultura/UFLA, Lavras-MG, e-mail: darlan@ufla.br

${ }^{4}$ Dr. Prof. Dep. de Ciência dos Alimentos/UFLA, Lavras-MG, e-mail: 1colima@ufla.br

${ }^{5}$ Dra. Pesquisadora da EPAMIG CTTP, C.P 351 CEP 38001-970 - Uberaba-MG, e-mail:ester@epamig.br

${ }^{6}$ Dr. Prof. Dep. de Agricultura/UFLA, Lavras-MG, e-mail: pcmelo@ufla.br
} 


\section{INTRODUÇÃO}

As áreas de cultivo e a produção do maracujá têm crescido nos últimos anos. De acordo com o Agrianual (2008), o Brasil produziu, em 2005, um total de 479.813 t. em uma área de 35.820 ha, sendo o Estado da Bahia o maior produtor (139.910 t.), seguido pelo Espírito Santo (51.070 t.), Pará (45.297 t.), Minas Gerais (44.025 t.) e Sergipe (41.526 t.). A produtividade média alcançada nos pomares brasileiros é bastante baixa $(13.395 \mathrm{~kg} / \mathrm{ha})$, bem inferior ao potencial produtivo da espécie que pode chegar a $30.000 \mathrm{~kg} / \mathrm{ha} / \mathrm{ano}$. Estima-se que $95 \%$ desta produção corresponde ao maracujá-amarelo (Passiflora edulis Sims.f. flavicarpa Deg.), também conhecido como maracujá-azedo.

Para o Estado de Minas Gerais, houve, no período de 2000 a 2005, um acréscimo de 229 ha na área plantada (Agrianual, 2008); isto significa bastante, pois estes cultivos são, na sua maioria, praticados em pequenas áreas. Segundo Costa et al. (2005), a cultura do maracujá gera em torno de seis empregos por hectare, sendo dois diretos e quatro indiretos. A atividade está associada à produção de base familiar.

Uma fruta de qualidade é aquela que atenda às expectativas dos diferentes segmentos consumidores, nas suas características internas e externas. As internas estão relacionadas ao sabor (teor de açúcares e acidez) e conteúdo de suco (rendimento); enquanto as externas, a aparência, associada aos parâmetros de padronização da fruta, representam muito na escolha pelo consumidor (Balbino, 2005).

Geralmente, utilizam-se os frutos de melhor aparência externa para o mercado de fruta fresca, enquanto os demais são destinados à industrialização. O Programa Brasileiro para a Melhoria dos Padrões Comerciais e Embalagens de Hortigranjeiros (Brasil, 2003) possui uma classificação própria para esta fruta. Suas classes são determinadas pelo diâmetro equatorial (transversal) do fruto, usando uma escala numérica (1-5). Segundo Meletti (1999), após a classificação da fruta, o produto de melhor qualidade é remunerado a preços significativamente superiores, até $150 \%$ a mais que o obtido com a comercialização dos frutos das classes inferiores, em determinadas épocas do ano.

São vários os fatores que podem interferir na produtividade e qualidade dos frutos do maracujazeiro, sendo os principais: temperatura, precipitação, umidade relativa, luminosidade e manejo cultural, exercendo importante influência na produção, longevidade do pomar, incidência de pragas e doenças na cultura (Lima \& Borges, 2002). De acordo com
Cavichioli et al. (2006), a redução da iluminação natural prejudica o florescimento, a frutificação e a produtividade do maracujazeiro-amarelo, sendo esse efeito possivelmente relacionado com a redução da taxa de fotossíntese, causada pela redução da luz e da temperatura no ambiente.

No sistema de condução em espaldeira, a poda de formação deve ser iniciada logo após o plantio das mudas no campo, deixando crescer uma haste única até ultrapassar o fio de arame, em aproximadamente $10 \mathrm{~cm}$, realizando-se a poda na altura deste fio. A partir deste deverão ser conduzidos (dois ramos secundários) sobre o fio de sustentação até atingir o ramo da outra planta, que serão podados (desponte), favorecendo a emissão dos ramos terciários ou produtivos. Estes crescerão livremente em direção ao solo, devendo ser podados a $20 \mathrm{~cm}$ do solo (Costa et al., 2005).

A poda de formação ou condução da planta tem por finalidade proporcionar uma estrutura de ramos adequados, com uma distribuição equilibrada destes, havendo o arejamento e iluminação convenientes (Sousa, 2005). Segundo as Normas Técnicas para a Produção Integrada de Maracujá (Brasil, 2005), é obrigatório conduzir a planta de forma a equilibrar a atividade vegetativa e a produção, propiciando boa distribuição dos ramos de modo a facilitar os tratos culturais e permitir maior insolação dos ramos produtivos.

A preocupação com a forma de implantação e a condução da lavoura tem sido uma constante entre os pesquisadores. O uso de espaçamentos adequados, podas e irrigação podem ser determinantes na produtividade e lucratividade do maracujazeiro (Silva et al., 2004; Araújo Neto et al., 2005), no entanto outras informações são necessárias para a melhoria do rendimento da lavoura e produção em épocas mais adequadas.

Portanto, o objetivo deste trabalho foi avaliar a produtividade e a qualidade dos frutos de maracujazeiro-amarelo submetido a poda dos ramos produtivos.

\section{MATERIAL E MÉTODOS}

O experimento foi instalado e conduzido, entre os meses de setembro de 2005 a julho de 2006 , num pomar comercial localizado no município de Lavras, Sul do Estado de Minas Gerais. As coordenadas geográficas do local são: $21^{\circ} 14^{\prime}$ de latitude sul, $45^{\circ} 58^{\prime}$ de longitude oeste e $916 \mathrm{~m}$ acima do nível do mar. As principais informações climatológicas do período são apresentadas na Figura 1. 
Os resultados da análise de solo feita de $0-20 \mathrm{~cm}$ de profundidade mostraram os seguintes valores: $\mathrm{pH}\left(\mathrm{H}_{2} \mathrm{O}\right)=6,8 ; \mathrm{P}($ Mehlich $)=35,8 \mathrm{mg} \cdot \mathrm{dm}^{-3}$; $\mathrm{K}=150 \mathrm{mg} \cdot \mathrm{dm}^{-3} ; \mathrm{Ca}^{2+}=4,1 \mathrm{cmol} \cdot \mathrm{dm}^{-3} ; \mathrm{Mg}^{2+}=1,2$ $\mathrm{cmol}_{\mathrm{c}} \cdot \mathrm{dm}^{-3} ; \mathrm{Zn}=3,9 \mathrm{mg} \cdot \mathrm{dm}^{-3} ; \mathrm{Fe}=113,2 \mathrm{mg} \cdot \mathrm{dm}^{-3}$; $\mathrm{Mn}=22,9 \mathrm{mg} \cdot \mathrm{dm}^{-3} ; \mathrm{Cu}=2,9 \mathrm{mg} \cdot \mathrm{dm}^{-3} ; \mathrm{B}=0,7 \mathrm{mg} \cdot \mathrm{dm}^{-3}$; $\mathrm{S}=37,2 \mathrm{mg} \cdot \mathrm{dm}^{-3} ; \mathrm{Al}^{3+}=0,0 \mathrm{cmol}_{\mathrm{c}} \cdot \mathrm{dm}^{-3} ; \mathrm{H}+\mathrm{Al}^{3+}=1,2$ $\mathrm{cmol} \cdot \mathrm{dm}^{-3} ; \mathrm{SB}=5,7 \mathrm{cmol}_{\mathrm{c}} \cdot \mathrm{dm}^{-3} ; \mathrm{T}=6,9 \mathrm{cmol}_{\mathrm{c}} \cdot \mathrm{dm}^{-3}$; $\mathrm{V}=82,6 \% ; \mathrm{MO}=2,5 \mathrm{dag} . \mathrm{kg}^{-1} ;$ Areia $=36$ dag. $\mathrm{kg}^{-1}$; Silte $=8$ dag. $\mathrm{kg}^{-1} ;$ Argila $=56$ dag. $\mathrm{kg}^{-1}$. As adubações de plantio e de cobertura foram efetuadas de acordo com a análise de solo, seguindo as recomendações de Souza et al. (1999).

Foram utilizadas mudas de maracujazeiroamarelo da seleção IAC-270, oriundas de sementes, com sessenta dias após a germinação, sendo plantadas no campo no dia 20-09-2005, em covas ( 40 x 40 x 40 $\mathrm{cm})$, abertas no espaçamento de $4 \mathrm{~m}$ entre plantas e 3 metros entre fileiras (830 plantas por hectare). Estas foram conduzidas em sistema do tipo espaldeira vertical, com um fio de arame esticado horizontalmente, a $180 \mathrm{~cm}$ do solo, sob mourões de eucalipto (a cada $4 \mathrm{~m})$.

A planta foi conduzida em haste única, usando como tutor barbante de algodão, até atingir aproximadamente $200 \mathrm{~cm}$, recebendo poda na altura do arame $(180 \mathrm{~cm})$. A partir da extremidade do ramo primário, foram selecionados dois ramos secundários e conduzidos no fio de arame, onde sofreram desponte ao atingirem o comprimento de $200 \mathrm{~cm}$. Destes surgiram os ramos terciários, que cresceram no sentido pendente (vertical) em direção ao solo, formando a conhecida 'cortina' de ramos produtivos, que foi podada com $160 \mathrm{~cm}$ de comprimento $(20 \mathrm{~cm}$ do solo). Esta formação só foi possível com a eliminação das gavinhas, utilizando tesoura de poda.

Os tratamentos de formação das plantas consistiram em diferentes quantidades de ramos produtivos ou terciários $(40 ; 30 ; 24 ; 20$ e 14 ramos por planta). O delineamento utilizado foi em blocos casualizados, com quatro repetições, sendo a parcela experimental composta por três plantas. A distribuição dos ramos produtivos foi feita em toda a extensão do ramo secundário $(200 \mathrm{~cm})$, de forma que ficassem uniformemente distribuídos no mesmo, até atingir o número correspondente aos tratamentos, ficando metade para cada ramo secundário $(20 ; 15 ; 12 ; 10 \mathrm{e}$ 7 ramos).

Durante o período experimental, ocorreram ataques de lagartas desfolhadoras Dione juno-juno e Agraulis vanilae-vanilae (Lepidoptera:Nymphalidae), dos percevejos Diactor billineatus e Holymenia clavigera (Hemíptera:Coreidae) e das doenças antracnose (Colletotrichum gloeosporioides) e verrugose
(Cadosporim sp.). Para minimizar esses problemas, foram efetuadas aplicações dos inseticidas Cartap BR e Lebaycid EC e dos fungicidas Folicur CE e Thiobel.

A necessidade hídrica das plantas foi complementada com irrigação usando o sistema de gotejamento, aplicando a água de forma suplementar nos períodos de estiagem. Devido ao tamanho reduzido da área e à presença constante das mamangavas (Xylocopa spp.), não foi adotada a prática de polinização artificial.

A colheita foi realizada de março a julho de 2006, com intervalo médio de três dias, coletando os frutos comerciais caídos ao solo, procedendo-se a contagem e pesagem dos mesmos. Considerou-se fruto comercial aquele não danificado e com peso igual ou superior a $50 \mathrm{~g}$. Os frutos destinados à análise laboratorial foram coletados aleatoriamente, dentre os frutos colhidos no dia 21 de maio de 2006, sendo a parcela experimental composta de cinco frutos.

As variáveis analisadas foram: produtividade e rendimento de suco $\left(\mathrm{kg}_{\text {.ha }}{ }^{-1}\right)$, número de frutos por planta, peso médio do fruto $(\mathrm{g})$, diâmetro longitudinal e transversal do fruto $(\mathrm{mm})$, relação diâmetro longitudinal/diâmetro transversal, espessura da casca $(\mathrm{mm})$, porcentagem de casca, suco e semente, sólidos solúveis totais (\%), acidez total titulável (\% de ácido cítrico), sólidos solúveis/acidez total e potencial hidrogeniônico $(\mathrm{pH})$.

A estimativa de produtividade foi obtida multiplicando a produção média por planta pelo número de plantas $\left(833 . \mathrm{ha}^{-1}\right)$, e o rendimento de suco $\left(\mathrm{kg} \cdot \mathrm{ha}^{-1}\right)$, multiplicando a produtividade pela porcentagem de suco em cada tratamento. O número de frutos por planta foi determinado pela contagem de todos os frutos passíveis de comercialização. O peso médio do fruto foi definido pela divisão do peso total pelo número de frutos por planta. Os parâmetros diâmetros longitudinal, transversal e a espessura da casca foram obtidos com o auxílio de paquímetro. As porcentagens de casca, semente e suco foram determinados a partir da pesagem dos componentes em balança digital, fazendo as devidas proporções. O teor de sólidos solúveis totais foi medido, sem diluição, por meio de um refratômetro digital, com compensação automática de temperatura. A acidez total titulável foi determinada usando $5 \mathrm{~mL}$ de suco, fenolftaleína como indicador e titulação com $\mathrm{NaOH}$ a $0,1 \mathrm{~N}$. O pH do suco foi obtido pela leitura direta em $\mathrm{pH}$-metro digital.

Os resultados foram submetidos à análise de variância (teste $\mathrm{F}, 5 \%$ ), e as médias dos dados, comparadas pelo teste de Sccott-Knott, a 5\% de pro- 
babilidade. O programa utilizado para as análises estatísticas foi o SISVAR (Ferreira, 2000).

\section{RESULTADOS E DISCUSSÃO}

$\mathrm{Na}$ análise de variância, foram encontradas diferenças significativas (teste $F, p<0,05$ ) para as variáveis: número de frutos por planta, produtividade, rendimento de suco, peso médio dos frutos e diâmetro longitudinal do fruto.

Na Figura 2, observamos um decréscimo na produção de frutos por planta à medida que é reduzido o número de ramos terciários. $\mathrm{O}$ maior número de frutos por planta $(94,25)$ foi conseguido no tratamento com maior quantidade de ramos terciário, e o menor (46,37), no tratamento com menor número de ramos terciários.

O resultado pode estar associado ao fato de o maracujazeiro produzir flores e frutos nos ramos novos em crescimento (Kavati, 1998). A redução do número de ramos terciários (produtivos) provocou a redução do número de gemas floríferas e, consequentemente, a floração e a produção por planta.

Percebe-se, na Figura 3, que as maiores produtividades de frutos (13.639 e $\left.13.212 \mathrm{~kg} \cdot \mathrm{ha}^{-1}\right)$ ocorreram nos tratamentos onde foram deixados os maiores números de ramos (30 e 40, respectivamente). Para os tratamentos com menor número de ramos terciários, a produtividade caiu, ficando em: $11.434 ; 9.174$ e $7.416 \mathrm{~kg} \cdot \mathrm{ha}^{-1}$, para 24; 20 e 14 terciários por planta, respectivamente. Comportamento semelhante foi encontrado para o rendimento de suco, que variou de 4.1434 a $2.471 \mathrm{~kg} \cdot \mathrm{ha}^{-1}$. Esses valores superaram os encontrados por Araújo Neto et al. (2005), onde a produtividade de frutos, na primeira safra, foi de $9.282 \mathrm{~kg}$ ha $^{-1}$, quando se utilizou a densidade de 830 plantas por hectare e sem o uso de podas dos ramos terciários.

A estimativa da produtividade de frutos e de suco $\left(\mathrm{kg} \cdot \mathrm{ha}^{-1}\right)$ mostrou comportamento bastante semelhante ao ocorrido para o número de frutos por planta. Isto é explicado, pois a variável entra no cálculo da produtividade por hectare, e a redução da produção individual reduziu diretamente o rendimento por área.

A rentabilidade da lavoura está diretamente ligada ao número de frutos produzidos e este ao número de ramos produtivos totais por área. Segundo Andrade Júnior et al. (2003), o aumento da densidade de plantio elevou a produção numa correlação direta com o acréscimo de frutos por área, apesar de o número de frutos por planta ser significativamente menor.

A porcentagem de casca, suco e semente dos frutos não foi afetada pela quantidade de ramos deixados por planta (Tabela 1). Os valores variaram de 60,69 a $63,64 \%$ de casca, 31,77 a $33,25 \%$ de suco e 4,48 a $6,45 \%$ de semente. O rendimento de suco foi semelhante ao encontrado por Borges et al. (2003), variando de 32,8 a $34,3 \%$ em experimento de adubação com nitrogênio e potássio, em maracujazeiroamarelo.

O peso médio do fruto e o diâmetro longitudinal foram influenciados pelos tratamentos (Tabela 2). As plantas com menor número de ramos terciários apresentaram frutos com maior peso e diâmetro longitudinal. Isto pode estar associado à relação fontedreno que existe na planta, pois o menor número de frutos diminui a concorrência entre eles, aumentando seu crescimento. Isto concorda com os resultados apresentados por Queiroga et al. (2008) com a cultura do melão, onde a diminuição do número de frutos possibilitou o aumento do seu tamanho. Segundo Chitarra \& Chitarra (2005), o número excessivo de frutos por planta resulta na redução do tamanho, causado pela menor relação entre folhas e frutos remanescentes na planta e um menor suprimento de água e nutrientes a eles.

Os resultados diferiram parcialmente dos encontrados por Accorsi et al. (1992). Neles a intensidade de poda não influenciou na produção e número de frutos por planta e por área, nas duas safras avaliadas, nem na soma de ambas. Porém, interferiu significativamente no peso dos frutos avaliados, onde os ramos podados mais curtos apresentaram os maiores pesos médios, semelhantes aos verificado neste trabalho.

O crescimento do fruto deu-se mais no sentido longitudinal do que no transversal (Tabela 2). Isso pode prejudicar a qualidade do fruto, pois de acordo com o Programa Brasileiro para a Melhoria dos Padrões Comerciais e Embalagens de Hortigranjeiros (Brasil, 2003), as classes são determinadas, usando uma escala numérica (1-5), pela medida do diâmetro equatorial (transversal) do fruto. Mesmo assim, os frutos colhidos e analisados, de todos os tratamentos, pertencem à classe $4(\geq 75 \mathrm{a}<85 \mathrm{~mm})$, ficando dentro de um padrão ótimo de classificação.

A relação diâmetro longitudinal/transversal, a espessura da casca, o teor de sólidos solúveis, a acidez total, a relação sólidos solúveis/aidez total e o pH dos frutos não foram afetados significativamente pelo número de ramos terciários por planta (Tabela 2).

$\mathrm{Na}$ comercialização, há uma preferência por frutos de casca mais fina por apresentarem maior rendimento de polpa por quilograma adquirido.Para Borges et al. (2003), os frutos de maracujazeiroamarelo apresentaram espessura média $8 \mathrm{~mm}$, sendo bem superiores aos encontrados neste trabalho, que 
variou de 6,3 a 6,69 mm (Tabela 2). Brito et al. (2005) encontraram diferenças na espessura da casca utilizando tratamentos com diferentes fontes e doses de adubos orgânicos, indicando que esta característica está diretamente ligada aos fatores nutricionais.

Outro fator de grande influência sobre as características físicas e químicas dos frutos de maracujá é em estádio de maturação. Silva et al. (2005) verificaram que, durante o amadurecimento, houve um aumento progressivo dos sólidos solúveis totais $\left(10,2\right.$ a $16,3^{\circ}$ Brix $)$ e da relação sólidos solúveis/ acidez $(2,04$ a 3,54$)$; no entanto, houve redução da acidez total (5,0 a 4,6 \% de ácido cítrico), não havendo variação do $\mathrm{pH}(2,6$ a 2,7). Esses valores são bastante semelhantes aos encontrados na Tabela 2 , já que os frutos foram colhidos quando caíam ao solo, num estágio de maturação bem avançado.

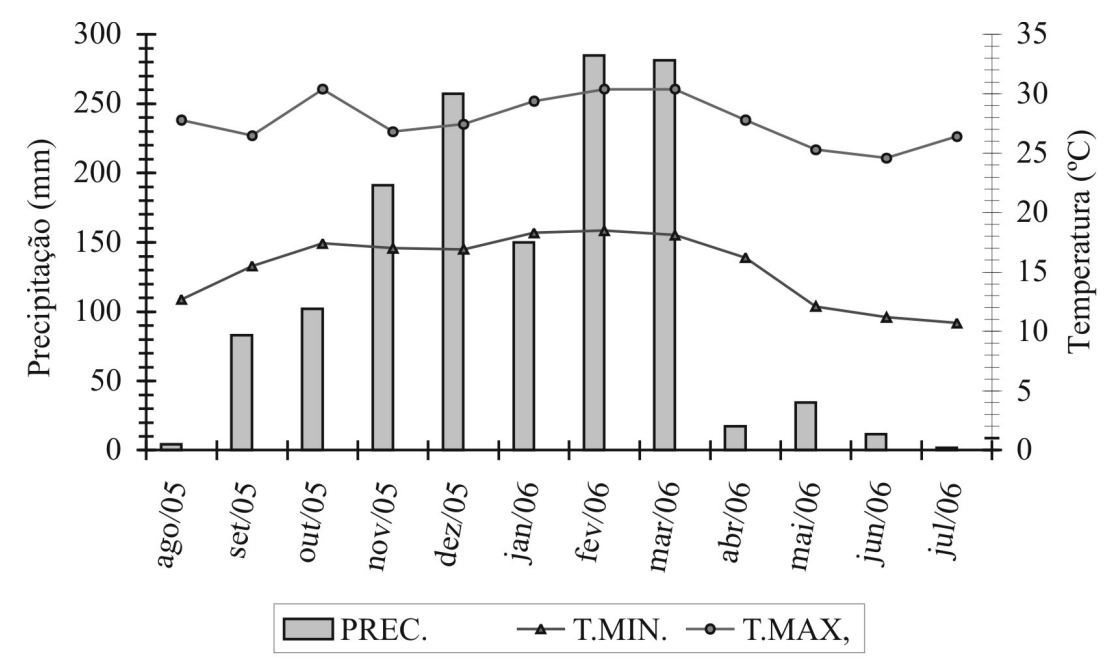

FIGURA 1 - Médias das temperaturas mínimas e máximas e da precipitação acumulada entre os meses de agosto de 2005 e julho de 2006.

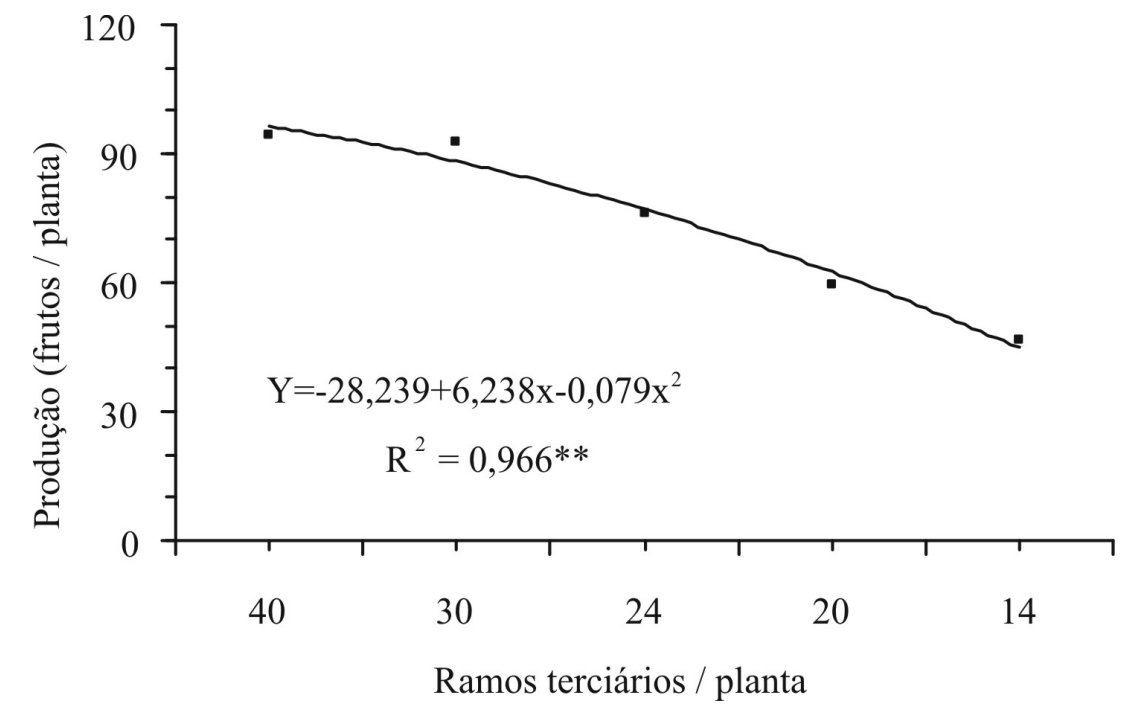

FIGURA 2 - Número de frutos por planta de maracujazeiro-amarelo nas diferentes formações da planta. 


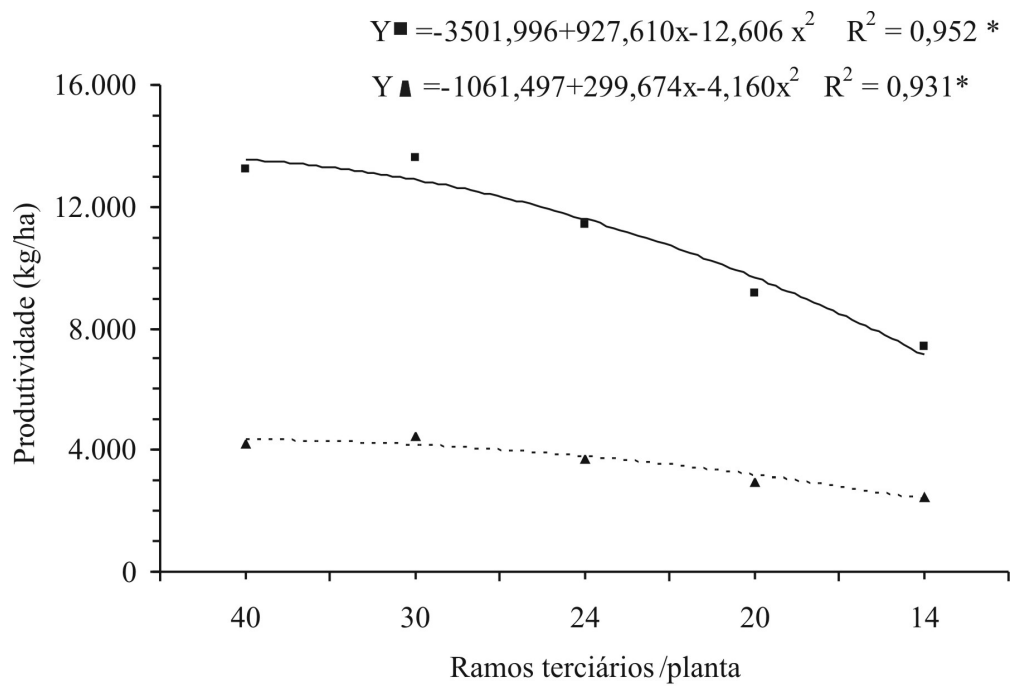

FIGURA 3 -Estimativa da produtividade de frutos e de suco de maracujazeiro-amarelo nas diferentes formações da planta.

TABELA 1- Rendimento de casca, suco e semente de maracujá-amarelo sob diferentes intensidades da poda de formação.

\begin{tabular}{cccc}
\hline $\begin{array}{c}\text { Tratamentos } \\
\text { (número de ramos } \\
\text { terciários) }\end{array}$ & Casca & Suco & Semente \\
\cline { 2 - 4 } & $63,63 \mathrm{a}$ & $31,77 \mathrm{a}$ & $4,59 \mathrm{a}$ \\
$\mathrm{T}_{1}=40$ & $62,33 \mathrm{a}$ & $32,39 \mathrm{a}$ & $5,27 \mathrm{a}$ \\
$\mathrm{T}_{2}=30$ & $62,95 \mathrm{a}$ & $32,55 \mathrm{a}$ & $4,48 \mathrm{a}$ \\
$\mathrm{T}_{3}=24$ & $62,55 \mathrm{a}$ & $32,13 \mathrm{a}$ & $5,31 \mathrm{a}$ \\
$\mathrm{T}_{4}=20$ & $60,69 \mathrm{a}$ & $33,25 \mathrm{a}$ & $6,45 \mathrm{a}$ \\
$\mathrm{T}_{5}=14$ & 4,39 & 4,88 & 36,35 \\
\hline $\mathrm{CV}(\%)$ & 62,43 & 32,42 & 5,22 \\
\hline Média & &
\end{tabular}

TABELA 2- Peso médio (PF); diâmetro longitudinal (DL) e transversal (DT); relação (DL/DT); espessura da casca (EC); sólidos solúveis totais (SS); acidez total titulável (AT); relação (SS/AT); e pH nos frutos de plantas de maracujazeiro, submetidas a diferentes intensidades de poda.

\begin{tabular}{cccccccccc}
\hline $\begin{array}{c}\text { Tratamentos } \\
\begin{array}{c}\text { Número } \\
\text { de ramos } \\
\text { terciários })\end{array}\end{array}$ & $\begin{array}{c}\mathrm{PF} \\
(\mathrm{g})\end{array}$ & $\begin{array}{c}\mathrm{DL} \\
(\mathrm{cm})\end{array}$ & $\begin{array}{c}\mathrm{DT} \\
(\mathrm{cm})\end{array}$ & DL/DT & $\begin{array}{c}\mathrm{EC} \\
(\mathrm{mm})\end{array}$ & $\mathrm{SS}$ & $\begin{array}{c}\text { AT } \\
(\%)\end{array}$ & SS/AT & $\mathrm{pH}$ \\
\hline $\mathrm{T}_{1}=40$ & $173,00 \mathrm{~b}^{*}$ & $84,81 \mathrm{~b}$ & $76,60 \mathrm{a}$ & $1,11 \mathrm{a}$ & $6,30 \mathrm{a}$ & $12,80 \mathrm{a}$ & $4,71 \mathrm{a}$ & $2,72 \mathrm{a}$ & $2,71 \mathrm{a}$ \\
$\mathrm{T}_{2}=30$ & $182,64 \mathrm{~b}$ & $86,55 \mathrm{~b}$ & $77,00 \mathrm{a}$ & $1,23 \mathrm{a}$ & $6,38 \mathrm{a}$ & $13,27 \mathrm{a}$ & $4,98 \mathrm{a}$ & $2,66 \mathrm{a}$ & $2,69 \mathrm{a}$ \\
$\mathrm{T}_{3}=24$ & $197,66 \mathrm{a}$ & $91,26 \mathrm{a}$ & $79,97 \mathrm{a}$ & $1,14 \mathrm{a}$ & $6,41 \mathrm{a}$ & $13,28 \mathrm{a}$ & $5,01 \mathrm{a}$ & $2,65 \mathrm{a}$ & $3,14 \mathrm{a}$ \\
$\mathrm{T}_{4}=20$ & $203,58 \mathrm{a}$ & $93,31 \mathrm{a}$ & $81,58 \mathrm{a}$ & $1,15 \mathrm{a}$ & $6,69 \mathrm{a}$ & $13,53 \mathrm{a}$ & $5,06 \mathrm{a}$ & $2,67 \mathrm{a}$ & $2,69 \mathrm{a}$ \\
$\mathrm{T}_{5}=14$ & $208,40 \mathrm{a}$ & $96,05 \mathrm{a}$ & $83,37 \mathrm{a}$ & $1,15 \mathrm{a}$ & $6,42 \mathrm{a}$ & $12,81 \mathrm{a}$ & $5,35 \mathrm{a}$ & $2,39 \mathrm{a}$ & $2,70 \mathrm{a}$ \\
$\mathrm{CV}(\%)$ & 4,27 & 5,58 & 5,78 & 5,68 & 5,90 & 7,58 & 7,40 & 7,49 & 13,48 \\
\hline Média & 193,10 & 90,39 & 79,71 & 1,16 & 6,48 & 13,14 & 5,02 & 2,62 & 2,79 \\
\hline
\end{tabular}

* Média seguidas de mesma letra, nas colunas, não diferem entre si, pelo teste de $\operatorname{Scott}-\operatorname{Knott}(\mathrm{P}<0,05)$. 


\section{CONCLUSÕES}

A partir dos resultados obtidos neste trabalho, é possível afirmar que:

1- As podas de formação com menor número de ramos terciários reduziram a produção de frutos por planta e a produtividade estimada.

2- Os frutos com maior peso médio e diâmetro longitudinal ocorreram nas plantas onde foram deixados o menor número de ramos terciários durante a formação da planta.

3-As características de qualidade interna dos frutos não foram afetadas pelas podas de formação da copa.

\section{AGRADECIMENTOS}

À Fundação de Amparo à Pesquisa do Estado de Minas Gerais (FAPEMIG) e à Coordenação de Aperfeiçoamento de Pessoal de Nível Superior (CAPES), pelo apoio financeiro ao projeto e concessão de bolsa de estudo.

\section{REFERÊNCIAS}

ACCORSI, M. R.; MANICA, I.; GAMA, F.S.N. da; KIST, H.G.K. Efeito da intensidade de poda sobre a produção do maracujá-amarelo em Eldorado do SulRS. Pesquisa Agropecuária Brasileira, Brasília, v.27, n.3, p.463-472, 1992.

AGRIANUAL 2008. Anuário da Agricultura Brasileira. São Paulo: FNP Consultoria, 2008.

ANDRADE JÚNIOR,V.C. de; ARAÚJO NETO, S.E.; RUFINI, J.C.M.; RAMOS, J.D. Produção de maracujazeiro-amarelo sob diferentes densidades de plantio. Pesquisa Agropecuária Brasileira, Brasília, v.38, n.12, p1381-1386, dez, 2003.

ARAÚJO NETO, S.E. de; RAMOS, J.D.; ANDRADE JÚNIOR, V. C. de; RUFINI, J.C.M.; MENDONÇA, V.; OLIVEIRA, T.K. de. Adensamento, desbaste e análise econômica na produção do maracujazeiroamarelo. Revista Brasileira de Fruticultura, Jaboticabal, v.27, n.3, p. 394-398, 2005.

BALBINO, J.M. de S. Manejo na colheita e pós-colheita do maracujá. In: COSTA, A. de F.S.; COSTA, A.N. (Eds.). Tecnologias para a produção de maracujá. Vitória-ES: INCAPER, 2005. p. 153-179.
BORGES, A.L.;RODRIGUES, M.G.V.; LIMA, A. de A.; CALDAS, R.C. Produtividade e qualidade de maracujá-amarelo irrigado, adubado com nitrogênio e potássio. Revista Brasileira de Fruticultura, Jaboticabal, v.25, n.2, p.259-262, agosto, 2003.

BRASIL. Ministério da Agricultura Pecuária e Abastecimento: Secretaria de Desenvolvimento Agropecuário e Cooperativismo. Normas Técnicas Específicas para a Produção Integrada de Maracujá. 2005. Disponível em: <www.agricultura.gov. br>. Acesso em: 15 jul. 2005.

BRASIL. Ministério da Integração Nacional. Programa Brasileiro Para a Melhoria dos Padrões Comerciais e Embalagens de Horticultura. 2003. Disponível em: <www.integracao.gov.br $>$. Acesso em: 23 out. 2003.

BRITO, M.E.B.; MELO, A.S. de; LUSTOSA, J.P.O.; ROCHA, M.B.; VIÉGAS, P.R.A.; HOLANDA, F.S.R. Rendimento e qualidade da fruta do maracujazeiro-amarelo adubado com potássio, esterco de frango e de ovino. Revista Brasileira de Fruticultura, Jaboticabal, v.27, n.2, p.260-263, 2005.

CAVICHIOLI, J.C. de; RUGGIERO, C.; VOLPE, A.; PAULO, E. M.; FAGUNDES, J.L.; KASAI, F.S. Florescimento e frutificação do maracujazeiroamarelo submetido à iluminação artificial, irrigação e sombreamento. Revista Brasileira de Fruticultura, Jaboticabal, v.28, n.1, p. 92-96, 2006.

CHITARRA, M.I.F.; CHITARRA, A.B. Pós-colheita de frutas e hortaliças: fisiologia e manuseio. 2. ed. Lavras:UFLA, 2005. 785p.

FERREIRA, D.F. SisVar ${ }^{\circledR}$ : Sistema de análise de variância para dados balanceados, versão 4.0. Lavras: DEX/UFLA, 2000. (Software estatístico).

COSTA, A. de F.S.; ALVES, F. de L.; COSTA, A.N. de. Plantio, formação e manejo da cultura do maracujá. In: COSTA, A. de F.S.; COSTA, A.N. de (Eds.). Tecnologias para a produção de maracujá. Vitória-ES: INCAPER, 2005. p. 23-53.

KAVATI, R. Florescimento e frutificação do maracujá-amarelo (Passiflora edulis f. flavicarpa) In: SIMPÓSIO BRASILEIRO SOBRE A CULTURA DO MARACUJAZEIRO, 5., 1998, Jaboticabal. Anais... Jaboticabal: FUNEP, 1998. p. 107-129. 
LIMA, A.A.; BORGES, A.L. Solo e clima. In: LIMA, A. A. Maracujá produção: aspectos técnicos. Brasília: EMBRAPA, 2002. p. 25-28.

MELETTI, L.M.M.; MAIA, M.L. Maracujá: produção e comercialização. Campinas, SP; IAC, 1999, 64 p. (Boletín Técnico, 181)

QUEIROGA, R.C.F.; PUIATTI, M.; FONTES, P.C.R.; CECON, P.R. Produtividade e qualidade de frutos de meloeiro variando o número de frutos e de folhas por planta.. Horticultura Brasileira, Jaboticabal, v.26, n.2, p. 209-215, 2008.

SILVA, H.A. de; CORRÊA, L. de S.; BOLLANI, A.C. Efeito do sistema de condução, poda e irrigação na produção de maracujazeiro-doce. Revista Brasileira de Fruticultura, Jaboticabal, v.26, n.3, p. 450-453, 2004.
SILVA, T.V.; RESENDE, E.D. de; VIANA, A.P.; ROSA, R.C.C.; PEREIRA, S.M. de F.; CARLOS, L.de A.; VITORAZI, L. Influência dos estádios de maturação na qualidade do suco do maracujá-amarelo. Revista Brasileira de Fruticultura, Jaboticabal, v.27, n.3, p.472-475, 2005.

SOUSA, J.S.I de. Poda das plantas frutíferas. São Paulo: Nobel, 2005, 191p.

SOUZA, M. de; GUIMARÃES, P.T.G.; CARVALHO, J.G. de; FRAGOAS, J.C. Maracujazeiro. In: RIBEIRO, A.C.; GUIMARÃES, P.T.C.; ALVAREZ, V.H. Recomendações para o uso de corretivos e fertilizantes em Minas Gerais. Viçosa: CFSEMG, 1999. p. 242-243. 